\title{
Forecasting daily net irrigation requirement maps of India using an ArcGIS toolbar
}

\author{
A. Bandyopadhyay ${ }^{1}$, K. Mahendra ${ }^{2}$ \& N. S. Raghuwanshi ${ }^{2}$ \\ ${ }^{I}$ Department of Agricultural Engineering, \\ North Eastern Regional Institute of Science and Technology, India \\ ${ }^{2}$ Department of Agricultural and Food Engineering, \\ Indian Institute of Technology Kharagpur, India
}

\begin{abstract}
Considering the vital importance of reference evapotranspiration (ETo) and net irrigation requirement (NIR) forecasts, a toolbar named Arc DSS_ET was developed to extend the capabilities of ESRI ArcGIS. The toolbar is capable of reading the five day forecasted meteorological data from India Meteorological Department (IMD) website for 75 stations all over India. An existing DSS_ET model was linked to the toolbar for estimation of ETo and thereby calculation of NIR for each station depending on the agro-ecological region (AER) in which it is situated. The toolbar was used to read data from IMD website from 4th November 2008 to 28th February 2009. These data were then used to estimate point ETo and NIR values and to prepare five days' forecasted maps of ETo and NIR by kriging. Four stations, namely, Ambala, Gadag, Jalpaiguri, and Pune, were selected to test the accuracy of forecasts. Most of the stations showed similar accuracy trends with higher accuracy for shorter lead time. It was also observed that the forecasts were slightly under predicted, but can be used up to five days as the error in forecasts were within acceptable range. Forecasted ETo, NIR, and rainfall were compared with the current day estimates and measurements in terms of Mean Absolute Error (MAE) for all five lead times for all the stations. Average MAE over AERs showed that error in ETo forecasts were also within acceptable range. Forecast accuracy of rainfall and NIR were found satisfactory except for mountaneous and coastal AERs 8, 15, 17, and 19 where frequent occurance of high variability rainfall was noticed.

Keywords: reference evapotranspiration, net irrigation requirement, forecasting, ArcGIS toolbar, ArcObjects, agro-ecological region.
\end{abstract}




\section{Introduction}

The sustainability of irrigated agriculture depends primarily on efficient water use. Efficient water use can be expressed as a function of potential atmospheric demand, which is expressed by reference evapotranspiration (ETo). Evapotranspiration, which includes evaporation (moisture loss from soil, standing water, etc.) and transpiration (biological use and release of water by vegetation) [1], is one of the most basic components of the hydrologic cycle. India receives about 400 million hectare meter ( $\mathrm{M}$ ha $\mathrm{m}$ ) water in the form of precipitation, of which $65 \%(260 \mathrm{M} \mathrm{ha} \mathrm{m})$ is lost through evapotranspiration. Thus, accurate estimation of ET is of paramount importance for net irrigation requirement. Mostly ETo estimation is done with the present or past data available. But it doesn't help the users for their field application or irrigation scheduling. If the ETo estimation is done for the forecasted meteorological data, it would be very helpful for the farmers, regional planners, researchers, etc.

ASCE [2] recognized FAO-56 Penman-Monteith (PM) [3] as the international standard ETo estimation method. However, FAO-56 PM method requires several meteorological data to be measured with sufficient accuracy to produce accurate estimates. Hargreaves and Samani [4] proposed a method for estimating ETo that requires only minimum and maximum air temperatures. In spite of being simple and requiring only measured temperature data, Hargreaves method proved to be the less impacted than Penman-type methods and well compared with them [5]. Hence FAO-56 PM and Hargreaves methods are recommended for ETo estimation in comprehensive and limited data availability conditions, respectively. Reddy [6] developed a decision support system (DSS) consisting of nine widely used ETo estimation methods, which was further modified to include 13 more methods and several other features [7-10] and was named as DSS_ET model. This model was used in this study for point ETo calculations.

ETo can be estimated at weather stations only, where required meteorological data are monitored. Estimates in other areas are usually obtained by interpolation of those point ETo values. Several interpolation methods, with various levels of complexity, exist. Kriging is the most widely used method among various geostatistical interpolation techniques and is well-proven. It also provides optimal interpolation and the best linear unbiased estimates [11].

Toolbars developed earlier like New LocClim [12], ArcET [13] and a toolbar developed with ArcObjects for ETo estimation [14], requires lot of data to be input. To work with these toolbars the user has to prepare the database in its specified format for ETo estimation. Even though, these toolbars are not envisioned for forecasting. Therefore, the present study was taken up to modify the existing DSS_ET model to automate and link it to a point coverage of meteorological stations within a GIS platform, to develop tools for reading meteorological data published in websites, updating point ETo estimates and contour maps for five days forecast, to develop tools for estimating point net irrigation requirements and generating daily net irrigation requirement maps of India for next five days, and to test the applicability of the developed tools by evaluating the accuracy of the forecasts. 


\section{Theoretical considerations}

\subsection{Estimation of ETo}

The FAO-56 Penman Monteith method [3] uses the following equation to calculate the reference evapotranspiration (ETo):

$$
\text { ETo }=\frac{0.408 \cdot \Delta \cdot\left(R_{n}-G\right)+\gamma \cdot \frac{900}{\left(T_{\text {mean }}+273\right)} \cdot u_{2} \cdot\left(e_{z}^{o}-e_{z}\right)}{\Delta+\gamma \cdot\left(1+0.34 \cdot u_{2}\right)}
$$

where, $R_{n}=$ net radiation at the crop surface, $\mathrm{MJ} \mathrm{m}^{-2} ; G=$ soil heat flux density $\approx 0$ (for daily basis calculation); $T_{\text {mean }}=$ mean air temperature, ${ }^{\circ} \mathrm{C} ; e^{o}{ }_{z}=$ saturation vapour pressure at mean air temperature, $\mathrm{kPa} ; e_{z}=$ actual vapour pressure at mean air temperature, $\mathrm{kPa} ; \Delta=$ slope of saturation vapour pressuretemperature curve, $\mathrm{kPa}^{\circ} \mathrm{C}^{-1} ; \gamma=$ psychometric constant, $\mathrm{kPa}^{\circ} \mathrm{C}^{-1}$ and $u_{2}=$ mean wind speed at $2 \mathrm{~m}$ above ground, $\mathrm{m} \mathrm{s}^{-1}$.

Hargreaves and Samani [4, 15] proposed several improvements over the original Hargreaves [16] equation for estimating grass ETo. Since solar radiation $\left(R_{S}\right)$ data are not routinely available everywhere, they recommended estimating $R_{s}$ from extraterrestrial radiation, $R_{a}$, and the resulting form of the equation is:

$$
\mathrm{ETo}=0.0023 \cdot \frac{1}{\lambda} \cdot R_{a} \cdot \sqrt{T D} \cdot\left(T_{\text {mean }}+17.8\right)
$$

where, $T D$ is the difference between maximum $\left(T_{\max }\right)$ and minimum $\left(T_{\min }\right)$ temperatures, ${ }^{\circ} \mathrm{C} ; R_{a}$ is extraterrestrial solar radiation in $\mathrm{MJ} \mathrm{m}^{-2} \mathrm{~d}^{-1}$ and $\lambda$ is latent heat of vaporization at $T_{\text {mean }}, \mathrm{MJ} \mathrm{kg}^{-1}$, which can be calculated for any air temperature $\left(T_{\text {air }},{ }^{\circ} \mathrm{C}\right)$ as:

$$
\lambda=2.501-0.002361 \cdot T_{\text {air }}
$$

In absence of sunshine hour data, solar radiation, $R_{s}$, can be estimated from the difference between maximum and minimum air temperatures as [15].

$$
R_{s}=K_{r} \cdot\left(T_{\max }-T_{\min }\right)^{0.5} \cdot R_{a}
$$

where, $K_{r}=$ an empirical coefficient. Hargreaves [17] recommended the value of $K_{r}$ to be 0.16 for interior regions and 0.19 for coastal regions.

\subsection{Estimation of net irrigation requirement}

The point ETo values, if multiplied by appropriate crop coefficient $\left(k_{c}\right)$ values can lead to crop ET $\left(\mathrm{ETc}=\right.$ ETo $\left.\mathrm{x} k_{c}\right)$. The $k_{c}$ values can be calculated following the single crop coefficient approach of Allen et al. [3]. The $k_{c}$ values for initial $\left(k_{c-i n i}\right)$, middle $\left(k_{c-i n i}\right)$, and end $\left(k_{c-e n d}\right)$ growth stages of different crops under typical irrigation management and soil wetting are given in Allen et al. [3]. Among these, use of the $k_{c-i n i}$ values is recommended for estimating ETc during preliminary or planning studies. However, the $k_{c-m i d}$ and $k_{c-e n d}$ values given in Allen et al. [3] are for $R H_{\text {min }}=45 \%$ and $u_{2}=2 \mathrm{~m} \mathrm{~s}^{-1}$. Hence, the standard table values $\left(k_{c}\right.$ Table $)$ of $k_{c-\text { mid }}$ and $k_{c-\text { end }}$ were corrected for normal $R H_{\min }$ other than $45 \%$ 
and normal $u_{2}$ larger or smaller than $2 \mathrm{~m} \mathrm{~s}^{-1}$ in the respective month and agroecological region as [3]:

$$
k_{c}=k_{\text {c Table }}+\left[0.04 \cdot\left(u_{2}-2\right)-0.004 \cdot\left(R H_{\min }-45\right)\right] \cdot\left(\frac{h_{c}}{3}\right)^{0.3}
$$

Effective rainfall $\left(R_{e}\right)$ is that part of precipitation that infiltrates into the soil and is available for crop use. It can be calculated either by the fixed percentage of rainfall method or USDA Soil Conservation Service method [18]. The fixed percentage method is given as:

$$
E R=a \cdot P_{T}
$$

USDA Soil Conservation Service method is given as:

$$
\begin{aligned}
E R & =P_{T} \frac{\left(125-0.2 P_{T}\right)}{125}, \text { if } P_{T} \leq 250 \mathrm{~mm} \\
& =125+0.1 P_{T}, \quad \text { if } P_{T} \geq 250 \mathrm{~mm}
\end{aligned}
$$

where, $E R=$ effective rainfall for crop, $\mathrm{mm} ; a=$ fixed percentage, fraction and $P_{T}=$ total precipitation, $\mathrm{mm}$.

The point effective rainfall values were then deducted from corresponding point ETc to determine the net irrigation requirement at each point. After estimation of NIR, these point values can be spatially interpolated by kriging to create net irrigation requirement maps.

\section{Data and methodology}

\subsection{Data acquisition}

A point coverage of India Meteorological Department (IMD) stations was prepared using Arc/INFO 9.2 (Fig. 1). The coverage contained fields for storing latitude longitude, name, state, elevation (m), corresponding website address to read the meteorological data from, downloaded meteorological data, calculated ETo and NIR.

Five days forecasts of meteorological data of the selected stations are available in IMD website [19]. Current day's weather data are available through a single webpage for all the stations [20]. The weather data available from the IMD website are maximum and minimum temperatures, maximum and minimum relative humidity's, rainfall and wind speed.

\subsection{Development of toolbar}

ArcObjects is a development platform for ArcGIS that allows developers to enhance and extend the data processing capabilities of GIS [21]. The interface and GIS functionality of the developed toolbar have been programmed with ArcObjects using VBA. The purpose of developing such toolbar was to free the user from complicated interactions required for ETo estimation and incorporating all functions into a custom ArcGIS toolbar. The toolbar estimates present day spatial evapotranspiration and net irrigation requirement as well as daily forecasts for next five days and is named as Arc DSS_ET (Fig. 2). 


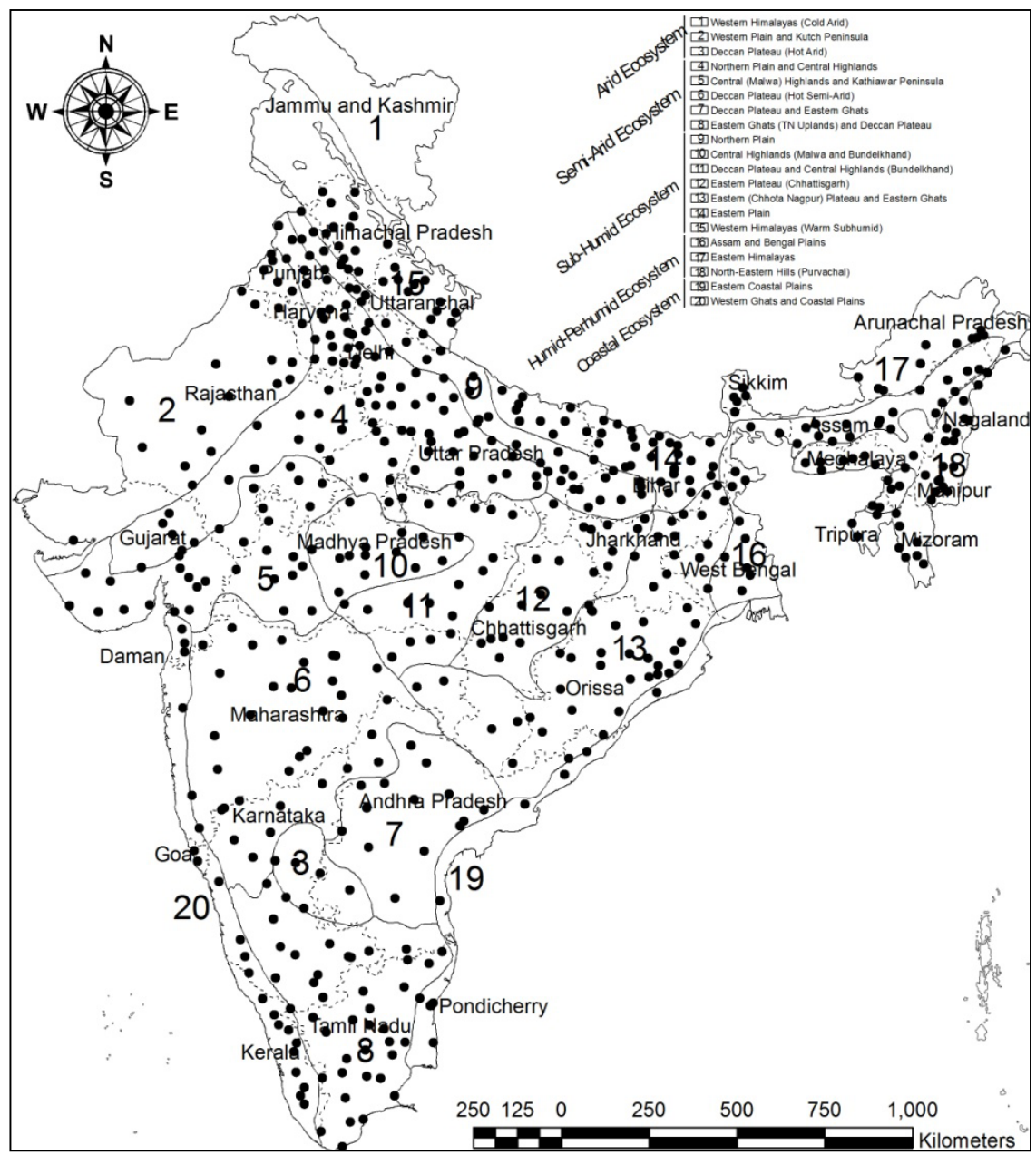

Figure 1: $\quad$ Agro-ecological regions of India and location of IMD stations.

\subsubsection{Update data}

The first tool Update Data consists of two submenus, Today's temperature and Rainfall and IMD Forecast, which are used for getting the meteorological data from the IMD website (Fig. 2). Today's Temperature and Rainfall submenu updates the current day's weather data. It first compares the station name on the website with the name specified in IMD coverage file (imd.shp) and data are updated in the respective fields for the stations with matching names. The IMD Forecast submenu is used for getting the forecasted weather data. IMD is providing five days forecast of weather data. By clicking this button, the available weather data forecasts can be downloaded and copied into the IMD stations coverage attribute table. 


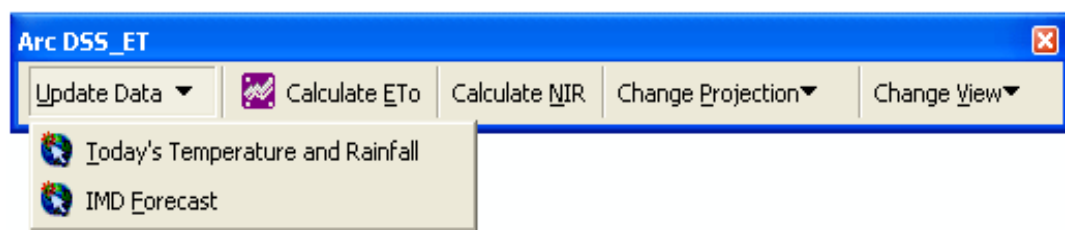

Figure 2: $\quad$ Arc DSS_ET toolbar.

\subsubsection{Calculate ETo using modified DSS_ET model}

The function of the Calculate ETo button is to call the modified DSS_ET model [7] for calculating ETo with the updated meteorological data for the selected point coverage of IMD station. Clicking this button on the toolbar brings up another window to select a method for ETo estimation. ETo can be estimated by two methods, viz., FAO-56 PM and Hargreaves methods. FAO-56 PM was selected as it is now considered as the sole international standard method for ETo estimation. However, this method requires comprehensive meteorological data. Hence, Hargreaves method was also included as it gives comparable results with temperature data only.

The DSS_ET model was modified to automate the point ETo estimation process at all the stations in the IMD Stations point coverage. The Arc DSS ET toolbar creates a New Data Input File (*.DIF) with the name of the station, which stores the station name, latitude, elevation, and meteorological data corresponding to that particular station from the attribute table. Particulars of data frequency period and data availability are also automatically specified in the DIF file as per the system date and the selected ETo calculation method.

Solar radiation being a required input parameter for FAO-56 PM method, it is also calculated by DSS_ET. The model provides five methods to calculate the missing solar radiation from the air temperature extremes. Hargreaves [17] method was selected to estimate missing solar radiation as it showed good results for Indian conditions [22]. Estimated ETo are exported to MS Excel file. These estimates are then automatically copied from the exported file to the IMD stations coverage attribute file. The ETo estimation process then automatically repeats for the next IMD station till all the stations are over.

\subsubsection{Calculate net irrigation requirement}

The function of Calculate NIR tool is to calculate net irrigation requirement with the estimated point ETo and rainfall at each IMD station. To get the point crop evapotranspiration (ETc), point ETo was multiplied by appropriate crop coefficient $\left(k_{c}\right)$ values depending on the area-wise main crop grown in the respective agro-ecological region and its stage of growth in a particular month [10]. NIR values can be spatially interpolated by ordinary kriging to create net irrigation requirement maps, as it showed encouraging results in similar study [10]. This approach was used with forecasted ETc and rainfall to derive forecasted net irrigation requirement map over the country. Thus forecasted ETo and NIR helps the users in making effective future plans. 


\subsubsection{Change projection and change view}

The fourth interactive tool in Arc DSS_ET toolbar is the Change Projection with two submenus. One is Polyconic that uses three dimensional spherical surface and displays the map in projected coordinate system. Second one is Geographic Lat Long that uses two dimensional representation and displays the map in geographical coordinate system. The Change View tool enables the map document to change its view between GIS Data View and Layout View.

\subsection{Spatial interpolation}

The kriging exercises were performed by the Geostatistical Analyst tool of ArcGIS 9.2 [23]. The Geostatistical Analyst tool assumes that the data is normally distributed. Hence the data were explored to check their distribution and to apply appropriate transformation when skewed. Ordinary kriging method was used to interpolate the current and forecasted estimates of ETo and NIR varying different parameters (transformation, order of trend removal, semivariogram model, anisotropy, number of lags and lag spacing, direction and extent of search, etc.). The maps created by best set of parameters in terms of cross-validation were accepted.

\subsection{Accuracy of IMD forecast}

Accuracies of the IMD forecasts and the resulting ETo and NIR forecasts were verified by comparing the forecasts with the current day values. One, two, three, four, and five day ahead forecasts were compared with their respective observed data when they were available. Four performance indicators (PI) were used for these comparisons, namely, modeling efficiency (ME), coefficient of residual mass (CRM), coefficient of determination $\left(r^{2}\right)$, and mean absolute error (MAE):

$$
\begin{gathered}
\mathrm{ME}=\frac{\sum_{i=1}^{n}\left(x_{o, i}-\bar{x}_{o}\right)^{2}-\sum_{i=1}^{n}\left(x_{p, i}-x_{o, i}\right)^{2}}{\sum_{i=1}^{n}\left(x_{o, i}-\bar{x}_{o}\right)^{2}} \\
\mathrm{CRM}=\frac{\sum_{i=1}^{n} x_{o, i}-\sum_{i=1}^{n} x_{p, i}}{\sum_{i=1}^{n} x_{o, i}} \\
r^{2}=1-\frac{\sum_{i=1}^{n}\left(x_{o, i}-x_{p, i}\right)^{2}}{\sum_{i=1}^{n}\left(x_{o, i}-\bar{x}_{o}\right)^{2}} \\
\mathrm{MAE}=\frac{1}{n} \sum_{i=1}^{n}\left|x_{p, i}-x_{o, i}\right|
\end{gathered}
$$

where, $\mathrm{n}=$ number of observations, $x_{p, i}=$ forecasted value, $x_{o, i}=$ current day value, and $\bar{x}_{o}=$ average of current day values. 


\section{Results and discussion}

\subsection{Accuracy of forecast at selected IMD stations}

Four stations, namely, Ambala, Gadag, Jalpaiguri, and Pune were selected for accuracy assessment based on location characteristics. The selected sites ranged in elevations from 83 to $661 \mathrm{~m}$ above mean sea level (MSL). The latitudes of these stations vary from $15.40^{\circ} \mathrm{N}$ to $30.34^{\circ} \mathrm{N}$ and the longitudes from $73.87^{\circ} \mathrm{E}$ to $88.70^{\circ} \mathrm{E}$. These four selected stations belong to different agro-ecological regions and are in different ecosystems. The toolbar was used daily from 04 Nov 2008 to 28 Feb 2009 to get the meteorological data. ETo and NIR were also estimated using the downloaded data using the Hargreaves method. Daily estimated current ETo were then compared with the corresponding forecasted ETo from previous days. The results of these comparisons in the selected four IMD stations showed that MAE increases, and ME and $\mathrm{r}^{2}$ decrease with increase in lead time of forecast.

Table 1 shows the four performance indicators (PI), namely, MAE, ME, $\mathrm{r}^{2}$, and CRM for different lead time forecasts, at selected four IMD stations. It can be said that the error in forecasting is very less for one day ahead forecasts. As the lead time in forecast increased, the error in forecasts also increased. CRM very close to zero indicated no systematic under- or over-estimation in forecasts.

Table 1: $\quad$ Comparison between ETo estimated with observed and forecasted data.

\begin{tabular}{|c|c|c|c|c|c|}
\hline PI & Lead time & Ambala & Gadag & Jalpaiguri & Pune \\
\hline \multirow{5}{*}{$\begin{array}{l}\text { Mean } \\
\text { Absolute Error } \\
\text { (MAE), } \mathrm{mm} \mathrm{d}^{-1}\end{array}$} & 1 day & 0.19 & 0.23 & 0.18 & 0.18 \\
\hline & 2 days & 0.24 & 0.28 & 0.24 & 0.24 \\
\hline & 3 days & 0.25 & 0.30 & 0.25 & 0.25 \\
\hline & 4 days & 0.28 & 0.31 & 0.28 & 0.28 \\
\hline & 5 days & 0.31 & 0.32 & 0.31 & 0.31 \\
\hline \multirow{5}{*}{$\begin{array}{l}\text { Modelling } \\
\text { Effeciency } \\
\text { (ME), fraction }\end{array}$} & 1 day & 0.80 & 0.79 & 0.83 & 0.83 \\
\hline & 2 days & 0.65 & 0.66 & 0.69 & 0.69 \\
\hline & 3 days & 0.66 & 0.66 & 0.62 & 0.62 \\
\hline & 4 days & 0.59 & 0.64 & 0.54 & 0.54 \\
\hline & 5 days & 0.46 & 0.63 & 0.42 & 0.42 \\
\hline \multirow{5}{*}{$\begin{array}{l}\text { Coefficient of } \\
\text { Determination } \\
\left(\mathrm{r}^{2}\right), \text { fraction }\end{array}$} & 1 day & 0.82 & 0.82 & 0.85 & 0.85 \\
\hline & 2 days & 0.72 & 0.71 & 0.73 & 0.73 \\
\hline & 3 days & 0.72 & 0.70 & 0.67 & 0.67 \\
\hline & 4 days & 0.65 & 0.68 & 0.61 & 0.61 \\
\hline & 5 days & 0.58 & 0.67 & 0.53 & 0.53 \\
\hline \multirow{5}{*}{$\begin{array}{l}\text { Coefficient of } \\
\text { Residual Mass } \\
\text { (CRM), } \\
\text { fraction }\end{array}$} & 1 day & 0.01 & 0.01 & 0.01 & 0.00 \\
\hline & 2 days & 0.01 & 0.01 & 0.00 & 0.00 \\
\hline & 3 days & 0.00 & 0.01 & 0.00 & 0.01 \\
\hline & 4 days & 0.00 & 0.01 & 0.00 & 0.01 \\
\hline & 5 days & 0.01 & 0.01 & 0.01 & 0.01 \\
\hline
\end{tabular}




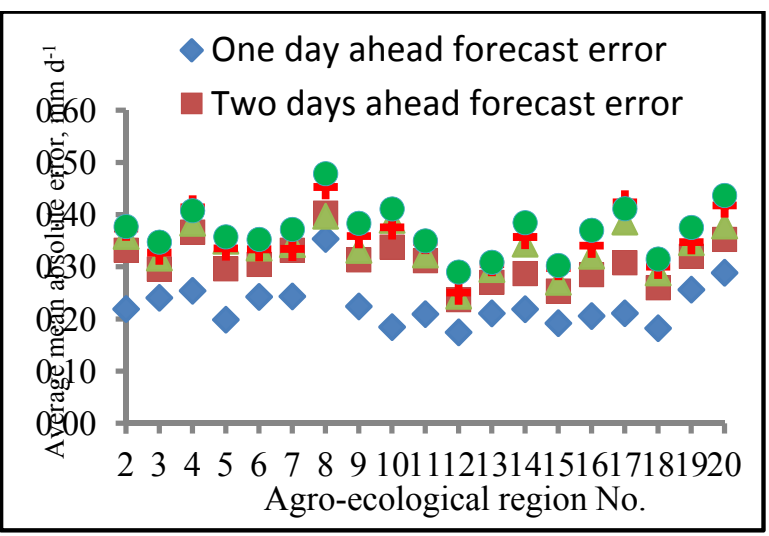

Figure 3: Average MAE in ETo forecasts over different AERs.

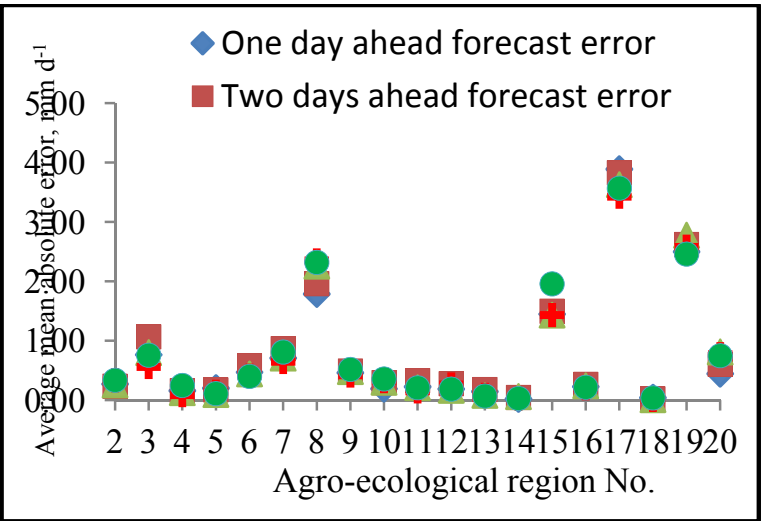

Figure 4: Average MAE in rainfall forecasts over different AERs.

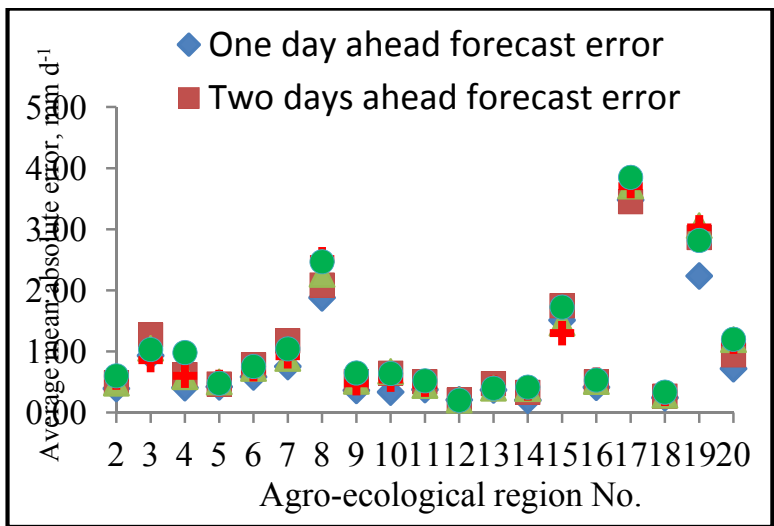

Figure 5: $\quad$ Average MAE in NIR forecasts over different AERs. 


\subsection{Accuracy of ETo and rainfall forecasts over AERs}

Similar to the stations reported above, accuracy estimation was done for all 75 stations. Forecasts of ETo and rainfall were compared with the current day estimates and measurements, respectively, to measure the accuracy of forecasts. The current day and forecasted ETo from 04 Nov 2008 to 28 Feb 2009 were compared in terms of MAE for all five lead times. Therefore, for each station, MAE of one, two, three, four, and five days ahead forecasts were estimated and average MAEs over different AERs was calculated (Fig. 3). Forecast errors for different lead times were compared. It was observed that the accuracy was decreased with the increase in forecast lead time. Maximum ETo forecast errors observed were $0.35,0.40,0.40,0.45$, and 0.48 for one, two, three, four, and five days ahead forecasts, respectively, for AER 8: Eastern Ghats (TN Uplands) and Deccan Plateau. Rainfall forecasts were also compared with observed values. Average MAEs over different AERs were estimated (Fig. 4). In most of the regions it was observed that the average MAEs were quite small. In the AERs 4, $5,12,13,14$, and 18 the average MAEs were close to zero. Average MAEs were observed to be higher in AER 8: Eastern Ghats (TN uplands) and Deccan Plateau, AER 15: Western Himalayas (Warm subhumid), AER 17: Eastern Himalayas, and AER 19: Eastern Coastal Plains. This was caused by frequent occurance of high variability rainfall in mountaneous regions and high lands.

\subsection{Estimation of NIR using developed tool}

Similarly, MAEs for NIR forecasts were also estimated (Fig. 5). The error was observed to be higher in AER 8,15, 17, and 19 because of the inaccuracy earlier reported in the rainfall forecasts. The accuracy of NIR is totally dependent on the rainfall forecasts.

\subsection{ETo and NIR maps}

After estimation of point ETo and NIRs, ETo and NIR maps were generated using kriging by ArcGIS 9.2 Geostatistical Analyst [23]. Generally, most of the crops are not irrigated daily. For this kind of crops, the forecasted ETo and net irrigation maps will be very helpful for irrigation planning. Daily one current day and five forecasted maps can be generated. So these forecasted maps can be useful for the crops having longer irrigation interval. One example forecasted NIR map is shown in Fig. 6.

\section{Conclusions}

The modified DSS_ET model is successfully linked to point coverage of IMD stations within a GIS platform. The developed Arc DSS_ET toolbar is successfully used to calculate point ETo and NIR and then to generate ETo and NIR forecast maps for next five days. It worked satisfactorily without any error during the test period of four months. Forecast error in ETo is found to be within acceptable range for all five lead times. Higher forecast accuracy is found for one 


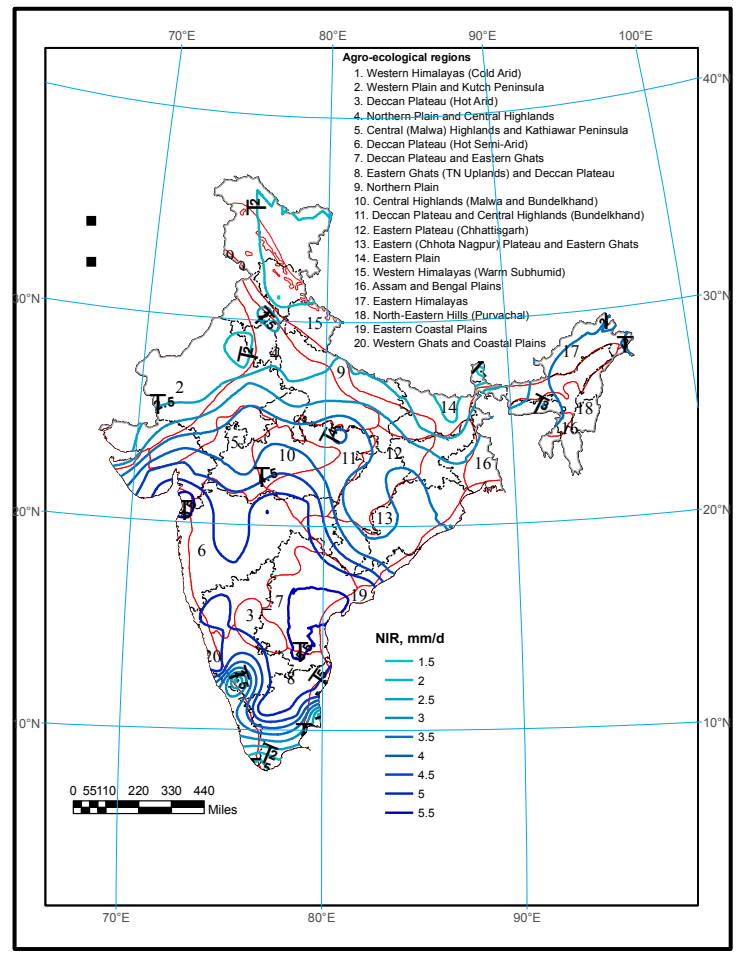

Figure 6: $\quad$ Five days ahead forecasted NIR map on 04-Nov-2008.

day ahead forecast followed by two, three, four, and five days' ahead forecasts. Rainfall forecast is found to be poor in AER 8,15, 17, and 19 compared to other AERs. The same error is propagated to NIR forecasts too. The five days forecasted NIR maps generated can be used for effective irrigation management.

\section{References}

[1] Hansen, V.E., Israelsen, O.W. \& Stringham, G.E., Irrigation principles and practices, $4^{\text {th }}$ Ed., John Wiley and Sons Inc., NY, USA, 1980.

[2] Itenfisu, D., Elliott, R.L., Allen, R.G. \& Walter, I.A., Comparison of reference evapotranspiration calculations as part of the ASCE standardization effort. J. Irrig. Drain. Engrg., 129(6), pp. 440-448, 2003.

[3] Allen, R.G., Pereira, L.S., Raes, D. \& Smith, M., Crop evapotranspiration - Guidelines for computing crop water requirements, Irrig. and Drain. Paper 56, Food and Agri. Org. of the UN (FAO), Rome, Italy, 1998.

[4] Hargreaves, G.H. \& Samani, Z.A., Reference crop evapotranspiration from temperature. Applied Engrg. in Agric., 1(2), pp. 96-99, 1985.

[5] Hargreaves, G.H. \& Allen, R.G., History and evaluation of Hargreaves evapotranspiration equation. J. Irrig. Drain. Engrg., 129, pp. 53-63, 2003. 
[6] Reddy, B.R.S., Development of a decision support system for estimating evapotranspiration, M. Tech. Thesis, Dept. of Agric. and Food Engrg., Indian Inst. of Technology (IIT), Kharagpur, WB, India, 1999.

[7] Bandyopadhyay, A., Bhadra, A., Swarnakar, R.K., Raghuwanshi, N.S. \& Singh, R., Estimation of reference evapotranspiration using a user-friendly decision support system: DSS_ET. Agric. Forest Meteorol., 154-155, pp. 19-29, 2012.

[8] Swarnakar, R.K. \& Raghuwanshi, N.S., DSS_ET user manual, Dept. of Agric. and Food Engrg., Indian Inst. of Technology (IIT), Kharagpur, WB, India, 2000.

[9] George, B.A., Reddy, B.R.S., Raghuwanshi, N.S. \& Wallender, W.W., Decision support system for estimating reference evapotranspiration. J. Irrig. Drain. Engrg., 128(1), pp. 1-10, 2002.

[10] Bandyopadhyay, A., Temporal and spatial trends of reference evapotranspiration in agro-ecological regions of India, Ph. D. Thesis, Dept. of Agric. and Food Engrg., Indian Inst. of Technology (IIT), Kharagpur, WB, India, 2008.

[11] Nalder, I.A. \& Wein, R.W., Spatial interpolation of climatic normals: Test of a new method in the Canadian boreal forest. Agric. For. Met., 92, pp. 211-225, 1998.

[12] Grieser, J., Gommes, R. \& Bernardi, M., New LocClim - the local climate estimator of FAO. Geophysical Research Abstracts, 8, 08305, 2006.

[13] Li, S., Tarboton, D. \& McKee, M., Development of an ArcMap toolbar for regional evapotranspiration modeling. Dept. Paper, Dept. of Civil and Environ. Engrg., Utah State University, Logan, Utah, USA, 2003.

[14] Latinopoulos, P., Papageorgiou, A. \& Mallios, Z., A visual basic toolbar for evapotranspiration estimation in GIS application. Proc. of the $9^{\text {th }}$ International Conference on Environmental Science and Technology, Rhodes Island, Greece, pp. 1175-1180, 2005.

[15] Hargreaves, G.H. \& Samani, Z.A., Estimating potential evapotranspiration. J. Irrig. Drain. Engrg., 108(3), pp. 225-230, 1982.

[16] Hargreaves, G.H., Moisture availability and crop production. Transactions of $A S A E$, 18(5), pp. 980-984, 1975.

[17] Hargreaves, G.H., Simplified coefficients for estimating monthly solar radiation in north America and Europe. Dept. Paper, Dept. of Biol. and Irrig. Engrg., Utah State University, Logan, Utah, USA, 1994.

[18] SCS, Irrigation water requirements, Technical Release 21 (TR-21), Soil Conservation Service (SCS), USDA, Washington, D.C., USA, 1970.

[19] http://www.imd.gov.in.

[20] http://www.imd.gov.in/section/nhac/dynamic/today.htm

[21] Zeiler, M., (ed). Exploring ArcObjects, Environmental System Research Institute Inc. (ESRI), California, USA, 2001.

[22] Bandyopadhyay, A., Bhadra, A., Raghuwanshi, N.S. \& Singh, R., Estimation of monthly solar radiation from measured air temperature extremes. Agric. For. Met., 148, pp. 1707-1718, 2008.

[23] ESRI, ArcGIS 9 - Using ArcGIS Geostatistical Analyst, Environmental System Research Institute Inc. (ESRI), California, USA, 2004. 